\title{
Evaluation of lipid lowering effect of milk thistle (silybum marianum) in comparison with rosuvastatin in rats by using ACE-Alera ${ }^{\circledR}$ analyzer
}

\author{
Fatima shahin ${ }^{\mathrm{a}}$, Eyad Mallah ${ }^{\mathrm{a}}$, Reem Emad ${ }^{\mathrm{a}}$, Luay Abu-Qatouseh ${ }^{\mathrm{a}}$, Wael Abu Dayyih ${ }^{\mathrm{a}}$, Feras Darwish El-hajji ${ }^{\mathrm{b}}$, Kenza \\ Mansoor $^{\mathrm{a}}$, Mona Bostami ${ }^{\mathrm{a}}$, Kamal Sweidan ${ }^{\mathrm{c}}$, Tawfiq Arafat ${ }^{\mathrm{d}}$. \\ a Faculty of Pharmacy and Medical Sciences, University of Petra, Amman, Jordan. \\ ${ }^{\mathrm{b}}$ Faculty of Pharmacy and Medical Sciences, Applied Science University, Amman, Jordan. \\ ${ }^{\mathrm{c}}$ Department of Chemistry, The University of Jordan, Amman, Jordan \\ d Jordan Center for Pharmaceutical Research, Amman-Jordan \\ Reprint requests to Prof. Dr. Eyad Mallah, E-mail: eyad782002@yahoo.com, emallah@uop.edu.jo \\ Faculty of Pharmacy and Medical Sciences, University of Petra \\ P.O.Box 961343, Amman 11196-Jordan, Phone: 00962(6)5715546, Fax 00962(6)5715570
}

Received: May 12, 2020. Revised: June 15, 2020. Accepted: July 10, 2020. Published: July 21, 2020.

Abstract-Dyslipidemia is a metabolic disorder that is characterized with an elevation in the cholesterol serum levels that can be treated with various hypolipidemic drugs like rosuvastatin. The present study was undertaken to determine and evaluate the hypolipidemic effect of milk thistle seeds extract in comparison with rosuvastatin and the combination of both for the treatment of dyslipidemia in rats. Also its effect on blood glucose levels on experimentally induced dyslipidemic rats. In vivo studies were conducted on wister albino laboratory rats, in which 49 rats were induced to be dyslipidemic by a daily intragastric administration of cholesterol $(2 \mathrm{~g} / \mathrm{kg})$. The induction of dyslipidemia was evaluated by comparing these rats with a negative control group that was composed of 10 healthy rats. Then, after one month dyslipidemia was induced in 49 rats that were divided into 6 groups, as the following; positive control group $(n=9)$ received cholesterol $(2 \mathrm{~g} / \mathrm{kg})$ for another one month, and the other five groups each of 8 rats continued to receive cholesterol $(2 \mathrm{~g} / \mathrm{kg})$ for one month along with therapy as; rosuvastatin low dose (RL) group received $10 \mathrm{mg} / \mathrm{kg}$, rosuvastatin high dose ( $\mathrm{RH}$ ) group received $20 \mathrm{mg} / \mathrm{kg}$, milk thistle (MT) group received $7.15 \mathrm{mg} / \mathrm{kg}$, (RL+MT) group received a combination of $10 \mathrm{mg} / \mathrm{kg}$ of rosuvastatin and $7.15 \mathrm{mg} / \mathrm{kg}$ of milk thistle, and $(\mathrm{RH}+\mathrm{MT})$ group received a combination of $20 \mathrm{mg} / \mathrm{kg}$ of rosuvastatin and $7.15 \mathrm{mg} / \mathrm{kg}$ of milk thistle. The statistical results of biochemical analysis showed that all the studied therapeutic protocols whether given alone; RL, RH, and MT or in a combination; RL+MT and RH+MT led to a significant $(\mathbf{p} \leq \mathbf{0 . 0 5})$ hypolipidemic effect that reduced the total cholesterol (TC), triglyceride (TG), low density lipoprotein (LDL) and very low density lipoprotein (VLDL) and increased the high density lipoprotein (HDL) cholesterol levels.
In conclusion, all therapeutic protocols were effective in treating dyslipidemia, as they all reduced the TC, TG, LDL, and VLDL, and increased the HDL cholesterol significantly $(\mathbf{p} \leq \mathbf{0 . 0 5})$. Furthermore, we found that milk thistle can be used in the management of dyslipidemia, as it has a hypolipidemic effect. Also, the addition of milk thistle to rosuvastatin therapy reduced the risk of developing diabetes mellitus (DM), as it has a glucose modulating activity either when it was given alone or in combination with rosuvastatin. Moreover, the combination of milk thistle and rosuvastatin was of a great benefit, as it gave an intensive goal of therapy than each one alone in altering all lipid profile parameters.

Keywords-cholesterol, dyslipidemia, milk thistle, rosuvastatin.

\section{INTRODUCTION}

A. Dyslipidemia

Cardiovascular diseases (CVD) are combined with other prevalent diseases such as diabetes mellitus (DM), hypothyroidism, renal insufficiency and dyslipidemia [1]. Dyslipidemia is a lipid metabolism disorder that is characterized by an elevation of serum levels of total cholesterol (TC), triglyceride (TG), and low density lipoprotein (LDL) cholesterol, along with low serum levels of high density lipoprotein (HDL) cholesterol [2]. It is diagnosed routinely via a serum lipid profile test that includes the four basic parameters; TC, TG, LDL and HDL [3], and is obtained after 10-12 hours of fasting, with complete dietary restriction, along with the exception of water and medication only [4]. Thus, dyslipidemia can be classified as hypercholesterolemia; in which the value of $\mathrm{TC}$ is greater than $240 \mathrm{mg} / \mathrm{dL}$ [5], combined dyslipidemia; in which the TC about $240-260$ $\mathrm{mg} / \mathrm{dl}$, TG about $200-400 \mathrm{mg} / \mathrm{dL}$ or even higher and LDL 
cholesterol above $190 \mathrm{mg} / \mathrm{dl}$ [4], [5], Hypoalphalipoproteinemia; in which the HDL cholesterol is less than $35 \mathrm{mg} / \mathrm{dL}$ [6], and hypertriglyceridemia; when the fasting serum TG levels exceed $200 \mathrm{mg} / \mathrm{dL}$ [7].

Elevated levels of cholesterol is considered as a common modifiable risk factor for dyslipidemia that can be managed by lifestyle modifications including smoking cessation and weight reduction, along with lipid regulating drug therapy [8], that includes mainly statins which are the most potent, most effective, and the best tolerated drugs for reducing $\mathrm{TC}$ and LDL cholesterol levels by inhibiting the HMG-CoA reductase which is the rate-limiting step of cholesterol synthesis [9].

B. Rosuvastatin

Rosuvastatin is available in the market as rosuvastatin calcium (Fig. 1) [10]. It is manufactured as film coated tablets for oral administration in 10, 20 and $40 \mathrm{mg}$. The presence of heptenoic acid fraction (Fig. 2) in rosuvastatin structure is the distinguishing statin pharmacophore that mimics the HMG portion of the HMG-CoA substrate. [11].

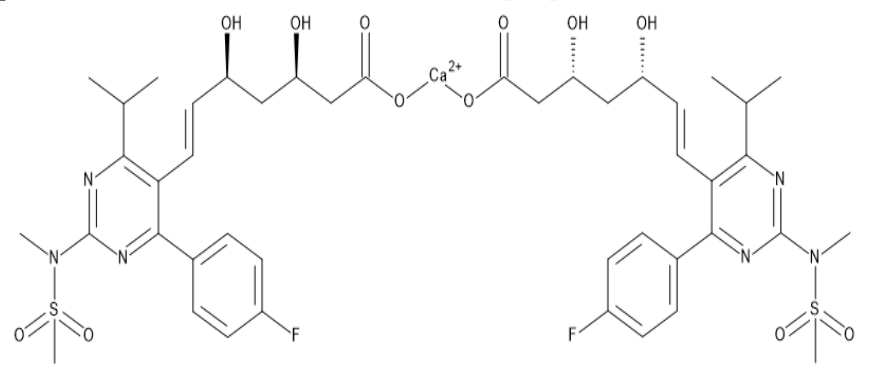

Fig. 1. Chemical structure of rosuvastatin calcium.<smiles>C=CCCCCC(=O)O</smiles>

Fig. 2. Chemical structure of heptenoic acid

Rosuvastatin was claimed to be a "super-statin" if compared with other statins in reducing LDL and increasing HDL cholesterol [11]. It is administered orally in the active form, once daily. The maximum peak plasma concentration (Cmax) is reached after 3 to 5 hours of oral administration, and with an approximate $20 \%$ bioavailability. Rosuvastatin is $88 \%$ bound reversibly to albumin plasma proteins. It is minimally metabolized by the cytochrome P450 (CYP 450) enzyme system, with little or no significant involvement of the 3A4 isozyme. While the CYP2C9 is the principal CYP isozyme involved in rosuvastatin metabolism [10]. 90\% of rosuvastatin is mainly eliminated from the body through biliary excretion as unchanged drug in the liver, while the remaining part is excreted in urine [12].

Rosuvastatin therapy may develop muscle cramps, aching and weakness in about $5-10 \%$ of patients, and in severe cases, myalgia, myopathy and rhabdomyolysis may be developed [7]. Moreover, rosuvastatin therapy was associated with a $9 \%$ of increased risk of the development of type $2 \mathrm{DM}$, by measuring the serum levels of fasting blood glucose (FBG) [13].

C. Milk Thistle

Milk thistle (silybum marianum) (Fig. 3) belongs to the asteraceae family, and is very well known for its' activity as hepato-protective agent for the treatment of hepatitis and gall bladder diseases, renal protective agent for restoring the electrolyte balance, pancreatic protective agent, antiinflammatory and antioxidant extract in which the seeds are the used part of it [14].
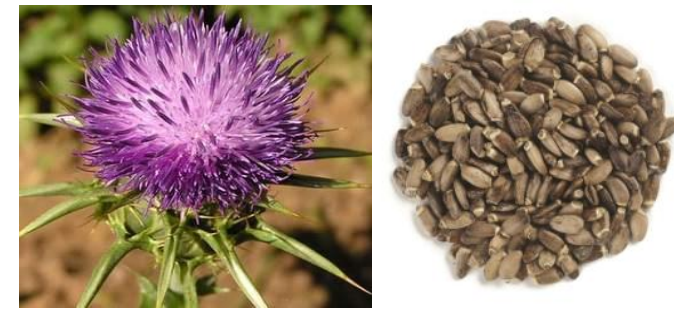

Fig. 3. Milk thistle flower and seeds

Milk thistle seeds are standardized to contain $80 \%$ of silymarin that is well known for its' hepatoprotectivity [14], thus it can be used for the treatment of various hepatobiliary disorders, such as hepatitis, cirrhosis, gallstones, and jaundice. Silymarin is a combination of flavonolignans that are silybin, isosilybin, silydianin and silychristin. Silybin (Fig. 4) is considered the most bioactive one, as it has a strong antioxidant activity that reduces free radicals and inhibits the lipid per-oxidation [15].<smiles>COc1cc([C@H]2Oc3cc(C4Oc5cc(O)cc(O)c5C(=O)[C@H]4O)ccc3OC2CO)ccc1O</smiles>

Fig. 4. Chemical structure of silybin flavonolignan. Reference [1] showed that the use of silymarin in a dose of $420 \mathrm{mg}$ once a day decreased cholesterol concentration in the bile of 15 patients when compared with the control group [1]. Also, Reference [16] showed that the administration of silymarin significantly reduced TC in plasma and caused more than twofold decrease in the very low density lipoprotein (VLDL) fraction [16]. Using the combination of herbs and pharmacological products to enhance the pharmacological action of some pharmaceutical products has been the quest of mankind since ancient times [17], [18], [19], [20].

Therefore, we aimed here to study and evaluate the hypolipidemic effect of milk thistle when it's used alone or in combination with rosuvastatin drug. And to evaluate its glucose lowering effect when it was given with rosuvastatin therapy, and the probability for developing DM.

II. Materials and methodology

A. Materials

Rosuvastatin calcium was obtained from joswe medical pharmaceutical company (amman-jordan). Milk thistle was purchased from sundown company (USA) as a standardized extract herbal supplement (175 mg per each capsule). Cholesterol was purchased from sigma-aldrich company (USA). Corn oil was obtained from the local market. Biochemical reagents along with the needed buffers were purchased from alfa-wassermann diagnostic technologies company (netherland). 
B. Quantitative biochemical analysis

The biochemical quantitative analysis was done for each rat in each group, and performed by using ACE-Alera ${ }^{\circledR}$ fully automated bench top clinical chemistry analyzer that is manufactured by alfa wassermann diagnostic technologies company [21]. Each rat was quantified for its FBG levels and lipid profile parameters including TC, TG, and HDL, and calculated for its LDL and VLDL levels using the modified friedewald formula (MFF) [22], as the following: $L D L$ cholesterol $=$ Non HDL cholesterol $\times 90 \%-T G \times$ $10 \%$

(1)

Non HDL cholesterol $=T C-H D L$ cholesterol (2)

$V L D L$ cholesterol $=T G / 5$ (3)

C. Preparation of Stock Solutions

Preparation of rosuvastatin stock solution

Rosuvastatin stock solution was prepared weekly by dissolving $200 \mathrm{mg}$ of rosuvastatin calcium in $100 \mathrm{ml}$ of distilled water, to get a drug solution of $0.2 \%(\mathrm{w} / \mathrm{v})$ concentration, which is equivalent to $2 \mathrm{mg} / \mathrm{ml}$ for each rat.

Preparation of milk thistle stock solution

Milk thistle stock solution was prepared weekly, by dissolving $143 \mathrm{mg}$ of milk thistle in $100 \mathrm{ml}$ of distilled water to get a solution of $0.143 \%(\mathrm{w} / \mathrm{v})$ concentration which is equivalent to $1.43 \mathrm{mg} / \mathrm{ml}$ for each rat.

Preparation of cholesterol stock solution

Cholesterol stock solution was prepared weekly by dissolving $40 \mathrm{~g}$ of cholesterol in $100 \mathrm{ml}$ of corn oil, and then mixed vigorously by using a blender to get a homogenous oily solution of $40 \%(\mathrm{w} / \mathrm{v})$ concentration of cholesterol which is equivalent to $400 \mathrm{mg} / \mathrm{ml}$ for each rat.

\section{Preclinical Study}

\section{Animal handling and study protocol}

The study protocol was approved by the ethical committee of the high research council in faculty of pharmacy and medical sciences, university of petra, amman-jordan (8/2017). Adult male and female wister-albino laboratory rats were supplied by the animal house of the applied science private university, with an average weight of $200 \mathrm{~g}$. They were placed in an airconditioned environment of $20-25^{\circ} \mathrm{C}$ and exposed to a photoperiod cycle (12 hours light/ 12 hours dark) daily. All rats were marked on their tails for the identification, weighed and randomized into seven groups.

Group \#1 was the negative control group, composed of 10 rats which were given the normal basal diet with a free access to water, and continued in the study for about 1 week under the same environmental conditions.

Group \#2 was the positive control group, composed of 9 rats which were given cholesterol in a dose of $2 \mathrm{~g} / \mathrm{kg}$ [23] as $1 \mathrm{ml}$ of the oily cholesterol solution in a concentration of 400 $\mathrm{mg} / \mathrm{ml} /$ rat daily for two months, administered by using a suitable oral gavage, along with their normal basal diet and a free access to water.

Group \#3, 4, 5, 6 and 7 were all of approximately 8 rats. All groups were given $1 \mathrm{ml}$ of cholesterol oily solution in a dose of $400 \mathrm{mg} / \mathrm{ml} / \mathrm{rat}$ daily for one month, for the purpose of dyslipidemia induction and continued for another one month during the dyslipidemia therapy. After four weeks, dyslipidemia was induced in all rats, then for another four weeks, rats were treated with either Rosuvastatin drug, or milk thistle seed extract, or a combination of both, and all were administered by using a suitable oral gavages.

Group \#3 was treated with a low dose of rosuvastatin which is $10 \mathrm{mg} / \mathrm{kg}$ [24] by being given $1 \mathrm{ml}$ of $0.2 \% \mathrm{w} / \mathrm{v}$ concentration of rosuvastatin solution daily, and so named with (RL group). Group \#4 was treated with a high dose of rosuvastatin which is $20 \mathrm{mg} / \mathrm{kg}$ [25] by being given $2 \mathrm{ml}$ of $0.2 \% \mathrm{w} / \mathrm{v}$ concentration of rosuvastatin solution daily, and so named with (RH group). Group \#5 was treated with milk thistle standardized seed extract, in a dose of $1.43 \mathrm{mg} / \mathrm{rat}$ which is equivalent to the human dose, by being given $1 \mathrm{ml}$ of $0.143 \% \mathrm{w} / \mathrm{v}$ of milk thistle solution daily, and so named with (MT group).

Group \#6 was treated with a combined therapy of milk thistle with a low dose of rosuvastatin calcium drug, by being given 1 $\mathrm{ml}$ of $0.143 \% \mathrm{w} / \mathrm{v}$ of milk thistle solution and $1 \mathrm{ml}$ of $0.2 \%$ $\mathrm{w} / \mathrm{v}$ of rosuvastatin calcium solution daily, and so named with (RL+MT group).

Group \#7 was treated with a combined therapy of milk thistle with a high dose of rosuvastatin calcium drug, by being given $1 \mathrm{ml}$ of $0.143 \% \mathrm{w} / \mathrm{v}$ of milk thistle solution and $2 \mathrm{ml}$ of $0.2 \%$ $\mathrm{w} / \mathrm{v}$ of rosuvastatin calcium solution daily, and so named with ( $\mathrm{RH}+\mathrm{MT}$ group).

The safety of this combination was proved by a study which showed that there is no interaction between rosuvastatin and milk thistle in which the pharmacokinetics of rosuvastatin is not altered by Silymarin [11]. This was also confirmed by another study which proved that the administration of milk thistle extract produced no significant effect on liver cytochromes including; CYP1A2, CYP2C9, CYP2D6, or CYP3A4 and CYP3A5 activities, so the occurrence of any pharmacokinetic interaction between rosuvastatin which is metabolized by CYP-2C9 and milk thistle was denied [26].

All these rat groups are described briefly in table I, along with their therapeutic regimens.

Samples collection and processing

Serum blood samples were obtained from the rats' optical vein after $12-14$ hours of fasting prior the samples collection, collected in labeled eppendrof tubes, they were left out for about 1 hour for good separation of blood serum from other blood contents, and they were immediately centrifuged at 5000 rpm for 10 minutes to get a clear non-hemolized serum blood sample, which were transferred into another labeled eppendrof tubes and stored at $-20^{\circ} \mathrm{C}$ until the biochemical analysis. Those samples were collected at zero time to determine the baseline measurements, then on weekly basis in order to follow up and evaluate the induction and the therapy of dyslipidemia.

Table I: Preclinical study design and rats grouping. 
INTERNATIONAL JOURNAL OF BIOLOGY AND BIOMEDICAL ENGINEERING

\begin{tabular}{|c|c|c|c|}
\hline Group Type & Group \# & Description & Duration \\
\hline $\begin{array}{c}\text { Negative (-) } \\
\text { Control }\end{array}$ & 1 & $\begin{array}{l}\text { \#10 rats; given the normal basal diet with a free } \\
\text { access to water. }\end{array}$ & 1 week \\
\hline $\begin{array}{c}\text { Positive }(+) \\
\text { Control }\end{array}$ & 2 & $\begin{array}{l}\text { \#9 rats; given } 1 \mathrm{ml} \text { of the }(2 \mathrm{~g} / \mathrm{kg}) \text { oily cholesterol } \\
\text { solution daily, along with their normal basal diet } \\
\text { and a free access to water. }\end{array}$ & 2 months \\
\hline \multirow[t]{6}{*}{$\begin{array}{l}\text { Treated } \\
\text { Groups }\end{array}$} & $\begin{array}{c}3,4,5,6 \\
\text { and } 7\end{array}$ & $\begin{array}{l}\text { Each group of \#8 rats; were given } 1 \mathrm{ml} \text { of ( } 2 \\
\mathrm{~g} / \mathrm{kg} \text { ) oily cholesterol solution daily, along with } \\
\text { their normal basal diet and a free access to water. }\end{array}$ & $\begin{array}{l}2 \text { months; } 1 \text { month } \\
\text { of induction and } 1 \\
\text { month of therapy }\end{array}$ \\
\hline & $3 ; \underline{\mathrm{RL}}$ & $\begin{array}{l}\text { Low dose of rosuvastatin; } 10 \mathrm{mg} / \mathrm{kg} \text {, by being } \\
\text { given } 1 \mathrm{ml} \text { of }(2 \mathrm{mg} / \mathrm{ml}) \text { drug solution. }\end{array}$ & 1 month of therapy \\
\hline & $4 ; \underline{\mathrm{RH}}$ & $\begin{array}{l}\text { High dose of rosuvastatin; } 20 \mathrm{mg} / \mathrm{kg} \text {, by being } \\
\text { given } 2 \mathrm{ml} \text { of }(2 \mathrm{mg} / \mathrm{ml}) \text { drug solution. }\end{array}$ & 1 month of therapy \\
\hline & $5 ; \underline{\mathrm{MT}}$ & $\begin{array}{l}\text { Milk thistle extract, by being given } 1 \mathrm{ml} \text { of }(1.43 \\
\mathrm{mg} / \mathrm{ml}) \text { herbal solution. }\end{array}$ & 1 month of therapy \\
\hline & $\begin{array}{c}6 ; \\
\text { RL+MT } \\
\end{array}$ & $\begin{array}{c}\text { "Combined Therapy 1": by being given } 1 \mathrm{ml} \text { of } \\
(1.43 \mathrm{mg} / \mathrm{ml}) \text { herbal solution and } 1 \mathrm{ml} \text { of }(2 \\
\mathrm{mg} / \mathrm{ml}) \text { drug solution. }\end{array}$ & 1 month of therapy \\
\hline & $\begin{array}{c}7 ; \\
\underline{\mathrm{RH}+\mathrm{MT}} \\
\end{array}$ & $\begin{array}{c}\text { "Combined Therapy 2": by being given } 1 \mathrm{ml} \text { of } \\
(1.43 \mathrm{mg} / \mathrm{ml}) \text { herbal solution and } 2 \mathrm{ml} \text { of }(2 \\
\mathrm{mg} / \mathrm{ml}) \text { drug solution. }\end{array}$ & 1 month of therapy \\
\hline
\end{tabular}

E. Statistical Analysis

Statistical analysis was performed by doing a one way analysis of the variance (one way ANOVA) test to determine whether there are any statistically significant differences between the means of these unrelated groups, and independent $t$ test that was performed between each two groups to determine whether there is a statistically difference between their means or not, by using SPSS statistics software (version 21). Each experimental value represents the mean \pm the standard error of the mean $(M \pm S E M)$. Probability value of 0.05 or less was considered significant ( $p$ value $\leq 0.05$ ).

III. Results and discussion

A. Induction of dyslipidemia

In the current study, dyslipidemia was induced for 49 healthy rats after one month of daily intragastric administration of cholesterol $(2 \mathrm{~g} / \mathrm{kg})$ oily solution. The results here were based on the baseline measurements before starting the study, compared with the measurements after one month, in which all rats were quantified for their $\mathrm{TC}$, TG, and $\mathrm{HDL}$, and calculated for their LDL and VLDL to evaluate their lipid profile, and also quantified for their FBG to evaluate their blood sugar.

Effect of cholesterol oily solution on serum lipid profile

This model was effective in inducing dyslipidemia in all rats, as it significantly $(\mathrm{p} \leq 0.01)$ increased the TC from 71.5 to 95 , TG from 51.9 to 117, LDL from 9.12 to 39.5 and VLDL from 10.38 to 23.4, and decreased the HDL from 52 to 38.11, (table II and fig. 5).

Effect of cholesterol oily solution on serum blood glucose sugar

This model was not effective in inducing DM in all experimental rats, as the statistical results showed that the increase of FBG from 69.2 to 71.33 was not significant $(p \leq 0.05)$, and this result is considered to be logical (table II and fig. 5).

Table II: Serum blood levels of TC, TG, LDL, VLDL, HDL, and FBG expressed in their mean for all rats, at the baseline and after one month of dyslipidemia induction.

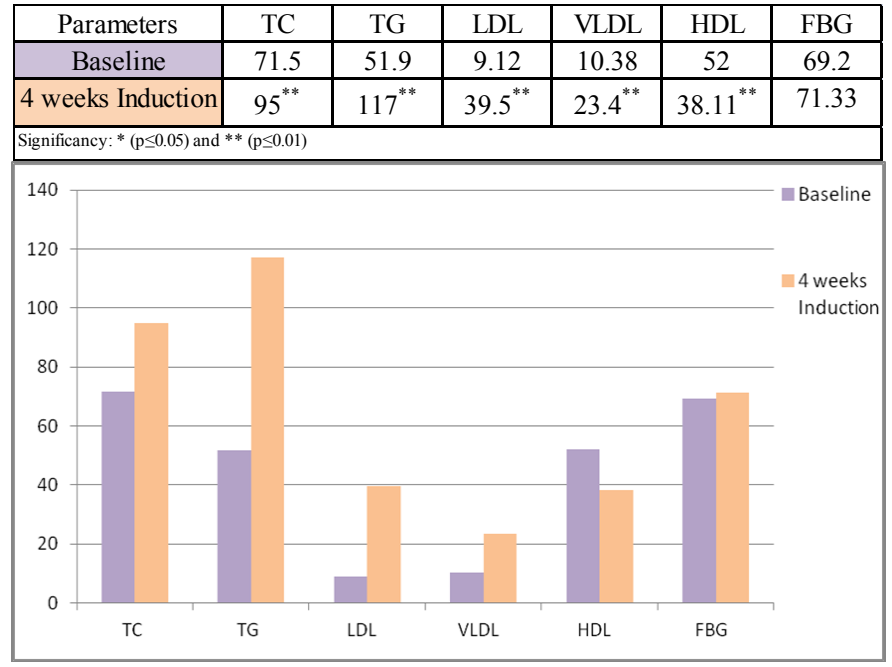

Fig. 5. Effect of intragastric administration of cholesterol (2 $\mathrm{g} / \mathrm{kg}$ ) on serum blood levels of TC, TG, LDL, VLDL, HDL, and FBG at the baseline and after 4 weeks of induction.

B. Modes of Dyslipidemia Therapy

Therapy was given as either rosuvastatin drug, milk thistle herb or a combination of both. The statistical analysis was done here for rats in all therapeutic groups compared with rats in the positive control group after 4 weeks of therapy.

Rosuvastatin Therapy

Effect of rosuvastatin on serum lipid profile

Rosuvastatin therapy at both doses was effective in treating dyslipidemia significantly $(\mathrm{p} \leq 0.01)$, as rosuvastatin $10 \mathrm{mg} / \mathrm{kg}$ decreased TC from 136.56 to 69.13 , TG from 149.56 to 60.88 , LDL from 76.34 to 16.86 and VLDL from 29.91 to 12.18 , and increased HDL from 35.11 to 43.63 , while rosuvastatin $20 \mathrm{mg} / \mathrm{kg}$ decreased TC from 136.56 to 62.63 , TG from 149.56 to 54.25 , LDL from 76.34 to 9.98 and VLDL from 29.91 to 10.85, and increased HDL from 35.11 to 45.5 (table III and fig. $6)$.

Effect of rosuvastatin on serum blood glucose sugar

Rosuvastatin therapy increased the risk of hyperglycemia, as FBS increased significantly $(\mathrm{p} \leq 0.01)$ from 65.89 to 93.88 for rats treated with rosuvastatin $10 \mathrm{mg} / \mathrm{kg}$, and from 65.89 to 98.63 for rats treated with rosuvastatin $20 \mathrm{mg} / \mathrm{kg}$ (table III and fig. 6). This emphasizes the results found in other studies; reference [13] found that the statin therapy was associated with a $9 \%$ increased risk of developing type 2 DM [13]. Another study showed that the incidence of DM was $6.5 \%$ in patients treated with rosuvastatin [27].

Table III: Serum blood levels of TC, TG, LDL, VLDL, HDL, and FBG expressed in their mean for all rats in RL and RH group compared with the positive control group after one month of therapy.

\begin{tabular}{|c|c|c|c|c|c|c|}
\hline Parameters & TC & TG & LDL & VLDL & HDL & FBG \\
\hline Positive Control & 136.56 & 149.56 & 76.34 & 29.91 & 35.11 & 65.89 \\
\hline RL $(10 \mathrm{mg} / \mathrm{kg})$ & $69.13^{* *}$ & $60.88^{* *}$ & $16.86^{* *}$ & $12.18^{* *}$ & $43.63^{* *}$ & $93.88^{* *}$ \\
\hline RH $(20 \mathrm{mg} / \mathrm{kg})$ & $62.63^{* *}$ & $54.25^{* *}$ & $9.98^{* *}$ & $10.85^{* *}$ & $45.5^{* *}$ & $98.63^{* *}$ \\
\hline
\end{tabular}




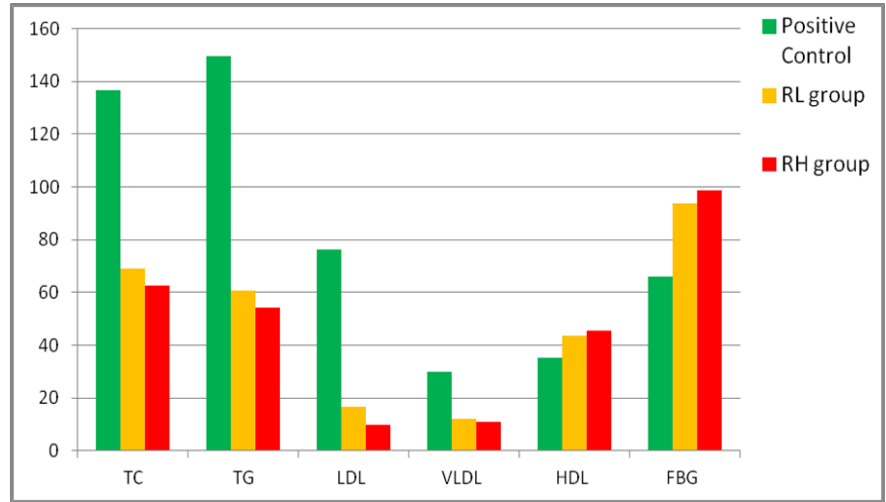

Fig. 6. Effect of rosuvastatin therapy on serum blood levels of TC, TG, LDL, VLDL, HDL, and FBG after one month compared with the positive control group.

Milk Thistle Therapy

Effect of milk thistle on serum lipid profile

Milk thistle was effective in treating dyslipidemia, as it significantly $(\mathrm{p} \leq 0.01)$ decreased TC from 136.56 to 69.63 , TG from 149.56 to 56.75 , LDL from 76.34 to 15.13 and VLDL from 29.91 to 11.35 , and increased HDL from 35.11 to 46.5 (table IV and fig. 7), thus it has a hypolipidemic activity.

Furthermore, MT therapy showed no significant differences with rosuvastatin therapy at both doses in hypolipidemic activity (table V and fig. 8), thus MT can be an alternative to rosuvastatin therapy.

Effect of milk thistle on serum blood glucose sugar

MT increased FBG from 65.89 to 73.25 , which is not significant when compared to the positive control group (table IV and fig. 7), but it was significantly $(p \leq 0.01)$ less than the elevations of FBG levels during rosuvastatin therapy at both doses (table V and fig. 8).

Table IV: Serum blood levels of TC, TG, LDL, VLDL, HDL and FBG expressed in their mean for all rats in MT group compared with the positive control group after one month of dyslipidemia therapy.

\begin{tabular}{|c|c|c|c|c|c|c|}
\hline Parameters & TC & TG & LDL & VLDL & HDL & FBG \\
\hline Positive Control & 136.56 & 149.56 & 76.34 & 29.91 & 35.11 & 65.89 \\
\hline Milk Thistle & $69.63^{* *}$ & $56.75^{* *}$ & $15.13^{* *}$ & $11.35^{* *}$ & $46.5^{* *}$ & 73.25 \\
\hline Significancy: ${ }^{*}(\mathrm{p} \leq 0.05)$ and ${ }^{* *}(\mathrm{p} \leq 0.01)$ \\
\hline 160 \\
\hline 100 \\
140
\end{tabular}

Fig. 7. Effect of MT on serum blood levels of TC, TG, LDL, VLDL, HDL and FBG after one month of therapy compared with the positive control group.

Table V: Serum blood levels of TC, TG, LDL, VLDL, HDL and FBG expressed in their mean for all rats in MT group compared with the rosuvastatin treated groups after one month of dyslipidemia therapy.

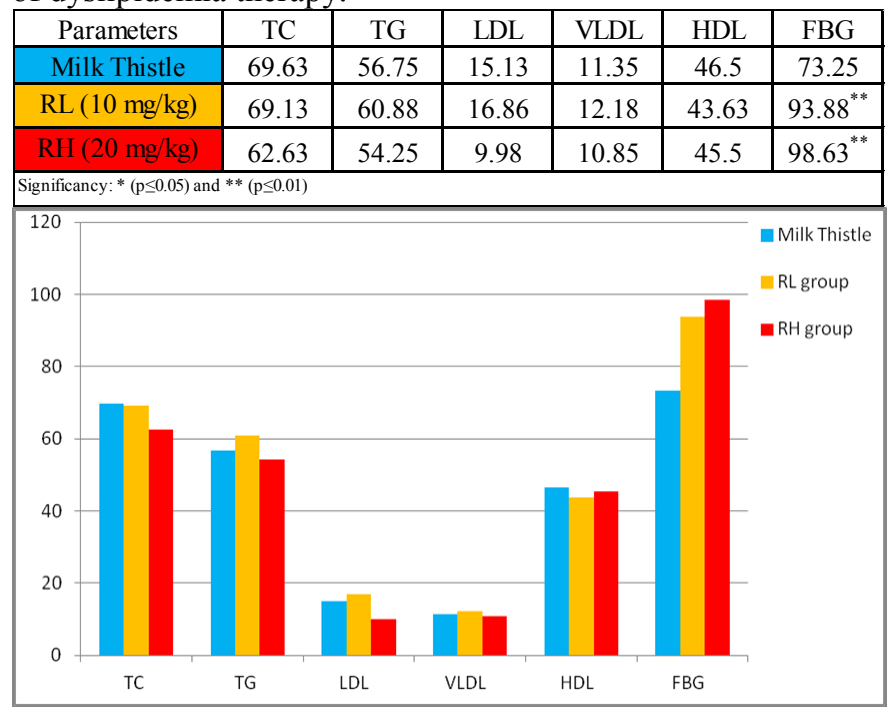

Fig. 8. Effect of MT on serum blood levels of TC, TG, LDL, VLDL, HDL and FBG after one month of therapy compared with the rosuvastatin treated groups.

Rosuvastatin and Milk Thistle Combination Therapy

Effect of combined therapy on serum lipid profile

The statistical results showed that RL+MT group significantly $(\mathrm{p} \leq 0.01)$ decreased TC from 136.56 to 63.88 , TG from 149.56 to 53.13 , LDL from 76.34 to 8.75 and VLDL from 29.91 to 10.63, and increased HDL from 35.11 to 48.25. Also, RH+MT group significantly $(\mathrm{p} \leq 0.01)$ reduced $\mathrm{TC}$ from 136.56 to 59.75, TG from 149.56 to 49.75 , LDL from 76.34 to 3.58 and VLDL from 29.91 to 9.95, and increased HDL from 35.11 to 50.25 , when both groups are compared with the positive control group (table VI and fig. 9), thus both therapeutic regimens have a hypolipidemic activity. Furthermore, there is no significant difference between RL+MT and $\mathrm{RH}$ group on reducing the TC, TG, LDL and VLDL or increasing HDL level (table VII and fig.10), thus this will give the ability to reduce the dose of rosuvastatin from 20 to $10 \mathrm{mg} / \mathrm{kg}$, so reduce its' side effects, while its' hypolipidemic effect can be compensated by the addition of milk thistle to the low dose of rosuvastatin.

Also, no significant difference between RH and RL+MT or $\mathrm{RH}+\mathrm{MT}$ group in reducing TC, TG and VLDL or in increasing HDL level, while the LDL was significantly $(p \leq 0.01)$ reduced more in RH+MT group (table VII and fig. 10), which indicated that the addition of MT to the high dose of rosuvastatin will give an intensive reduction in LDL levels, when compared to the effect of the drug alone.

Effect of combined therapy on serum blood glucose levels

The statistical results for RL+MT group showed a significant $(\mathrm{p} \leq 0.05)$ increase in FBG from 65.89 to 81.38 when compared to positive control group (table VI and fig. 9), which is in a lower intense than rosuvastatin therapy alone, that showed a significant $(\mathrm{p} \leq 0.01)$ increase of FBG from 65.89 to 93.88 for rats in RL group, and from 65.89 to 98.63 for rats in $\mathrm{RH}$ group. While, $\mathrm{RH}+\mathrm{MT}$ group showed a significant $(\mathrm{p} \leq 0.01)$ increase in FBG from 65.89 to 84.5 when compared to the positive control group (table VIand fig. 9). 
Table VI Serum blood levels of TC, TG, LDL, VLDL, HDL and FBG expressed in their mean for all rats in $(\mathrm{RL}+\mathrm{MT})$ and $(\mathrm{RH}+\mathrm{MT})$ treated groups compared with the positive control after one month of therapy.

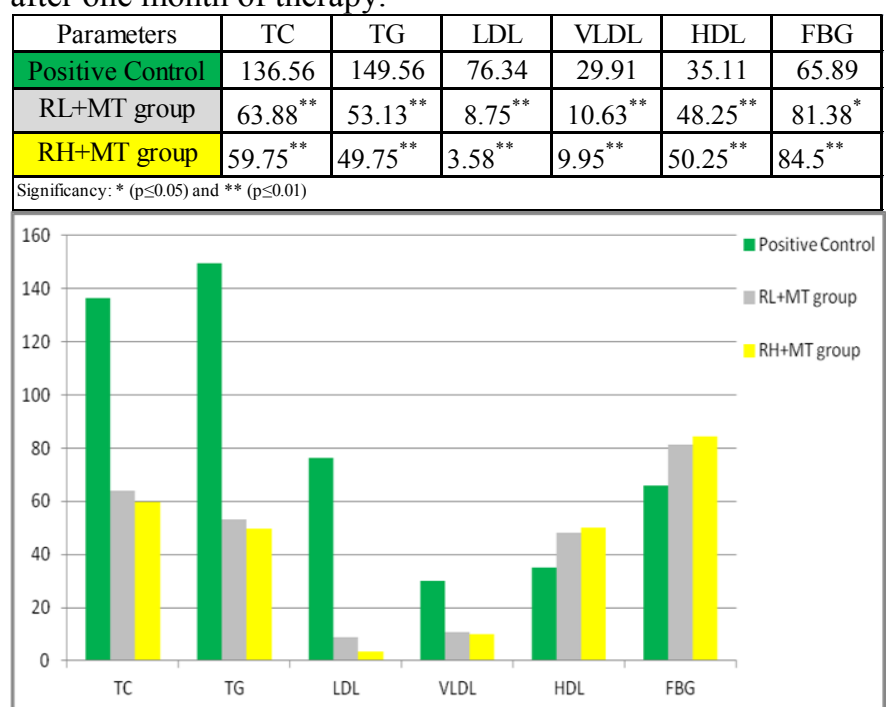

Fig. 9: Effect of combined therapy; (RL+MT) and (RH+MT) groups on serum blood levels of TC, TG, LDL, VLDL, HDL and FBG compared with the positive control after one month of therapy.

Table VIl Serum blood levels of TC, TG, LDL, VLDL, HDL and FBG expressed in their mean for all rats in $(\mathrm{RL}+\mathrm{MT})$ and $(\mathrm{RH}+\mathrm{MT})$ groups compared with the $\mathrm{RH}$ group after one month of therapy.

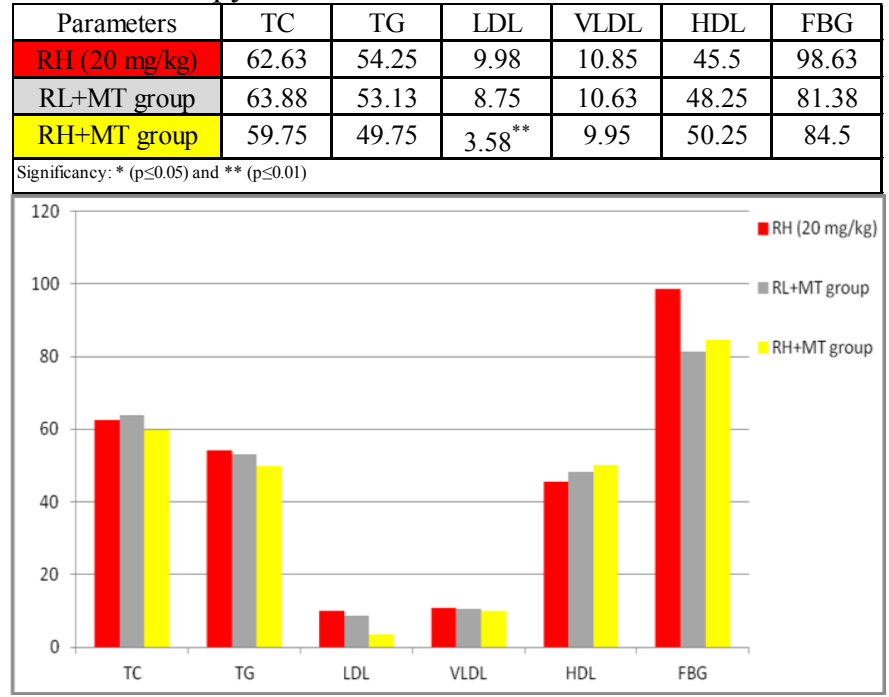

Fig. 10: Effect of combined therapy; (RL+MT) and (RH+MT) groups on serum blood levels of TC, TG, LDL, VLDL, HDL and FBG compared with the RH group after one month of therapy.

IV. Conclusion

The intragastric administration of cholesterol was significantly $(p \leq 0.01)$ effective in inducing combined dyslipidemia in all studied rats, by increasing the serum levels of TC, TG, LDL and VLDL, and decreasing the HDL. All therapeutic protocols of rosuvastatin drug, milk thistle seed extract, or their combination had a hypolipidemic activity that altered all lipid profile parameters, as they reduced the TC, TG, LDL and
VLDL, and increased the HDL serum blood levels. Both doses of rosuvastatin showed a comparable hypolipidemic effect and the same capability in inducing FBG thus increasing the risk of hyperglycemia. Also, milk thistle was seen to be effective in treating dyslipidemia, as it showed an effective hypolipidemic activity, thus it can be used as an alternate for rosuvastatin therapy to some extent with fewer side effects. The combination of milk thistle and rosuvastatin showed an intensive therapy than each one alone in altering all lipid profile parameters thus in treating dyslipidemia. And the good advantage for the addition of MT to rosuvastatin therapy in the study design was achieved in reducing the elevated levels of FBG that had been seen with rosuvastatin therapy and therefore, the risk of developing DM would be diminished.

V.Future work

In vitro studies should be conducted to evaluate the possible effect of MT flavanoids on the activity of HMG-CoA reductase enzyme. Furthermore, this study can be clinically conducted and applied on human volunteers.

Acknowledgment

The author would like to extend their appreciation to the deanship of scientific research at University of Petra for financial support and Applied Science University.

[1] M. Bahmani, M. Mirhoseini, H. Shirzad, M. Sedighi, N. Shahinfard, and M. Rafieian-kopaei, 'A Review on Promising Natural Agents Effective on Hyperlipidemia', vol. 20, no. 3, pp. 228-238, 2015.

[2] N. a. Qinna, B. S. Kamona, T. M. Alhussainy, H. Taha, A. a. Badwan, and K. Z. Matalka, 'Effects of Prickly Pear Dried Leaves, Artichoke Leaves, Turmeric and Garlic Extracts, and Their Combinations on Preventing Dyslipidemia in Rats', ISRN

Pharmacol., vol. 2012, pp. 1-7, 2012.

[3] P. K. Nigam, 'Serum lipid profile: Fasting or nonfasting?', Indian J. Clin. Biochem., vol. 26, no. 1, pp. 96-97, 2011.

[4] E. Tai et al., 'Ministry of Health Clinical Practice Guidelines: Lipids', Singapore Med. J., vol. 58, no. 3, pp. 155-166, 2017.

[5] T. F. Ashavaid, A. K. Altaf, and K. G. Nair, 'Molecular basis of familial hypercholesterolemia: An Indian experience.', Indian J. Clin. Biochem., vol. 15, no. Suppl 1, pp. 11-9, 2000.

[6] P. a Corris, 'A practical approach to the diagnosis of venothromboembolism.', Clin. Med., vol. 1, no. 4, pp. 274-281, 2002.

[7] L. Berglund et al., 'Evaluation and treatment of hypertriglyceridemia: An endocrine society clinical practice guideline', J. Clin. Endocrinol. Metab., vol. 97, no. 9, pp. 2969-2989, 2012.

[8] A. M. Gotto, 'Management of dyslipidemia.', Am. J. Med., vol. 112 Suppl, p. 10S-18S, 2002.

[9] Y. Liu, M. Manchekar, Z. Sun, P. E. Richardson, and N. Dashti, 'Apolipoprotein B-containing lipoprotein assembly in microsomal triglyceride transfer proteindeficient McA-RH7777 cells.', J. Lipid Res., vol. 51, 
no. 8, pp. 2253-64, 2010.

[10] A. G. Olsson, 'Rosuvastatin: a highly effective new HMG-CoA reductase inhibitor.', Cardiovasc. Drug Rev., vol. 20, no. 4, pp. 303-328, 2002.

[11] M. Ahmad, 'Pharmacokinetic Interactions of Rosuvastatin : A Review', vol. 2, pp. 1-7, 2012.

[12] Y. Shitara and Y. Sugiyama, 'Pharmacokinetic and pharmacodynamic alterations of 3-hydroxy-3methylglutaryl coenzyme A (HMG-CoA) reductase inhibitors: Drug-drug interactions and interindividual differences in transporter and metabolic enzyme functions', Pharmacol. Ther., vol. 112, no. 1, pp. 71105, 2006.

[13] N. Sattar, D. Preiss, and H. M. Murray, 'Statins and risk of incident diabetes: A collaborative meta-analysis of randomised statin trials', Revista Portuguesa de Cardiologia, vol. 29, no. 6. pp. 1077-1078, 2010.

[14] J.Murphy, 'Milk thistle (Silybum marianum)', Am. J. Heal. Pharm., vol. 56, no. 12, pp. 1195-1195, 1999.

[15] H. Thimbleby, 'Evaluation of blood chemical, lipids profile and immune response on broiler chicks fed with milk thistle (Silybum marianum L.) and thyme (Thymus vulgaris L.) seeds in south-eastern Iran', Vet. Sci. Dev., vol. 5, no. 243, pp. 21-24, 2015.

[16] L. Sobolova, N. Skottov, R. Ve`, and K. Urb, 'Effect of silymarin and its polyphenolic fraction on cholesterol absorption in rats ', Pharmacol. Res., vol. 53, pp. 104-112, 2006.

[17] Reem Emad, Eyad Mallah, and Fatima Shahin 'Determination Of Carbamazepine In Rat Plasma By Using High Performance Liquid Chromatography (Hplc) In Presence Of Some Traditional Beverages (Tamarind, Mango, Sugarcane, Red Bull) And Its PHARMACOKINETIC APPLICATIONS', Int. J. Biol. Pharm. Altied Sci., vol. 7, no. 11, pp. 19081921, 2018.

[18] E. Mallah et al., 'pharmacokinetics of Sildenafil in rats', vol. 38, no. 4, pp. 295-300, 2017.

[19] M. Alnaqeeb, K. A. Mansor, E. M. Mallah, B. Y. Ghanim, N. Idkaidek, and N. A. Qinna, 'Critical pharmacokinetic and pharmacodynamic drug-herb interactions in rats between warfarin and pomegranate peel or guava leaves extracts', vol. 5, pp. 1-12, 2019.

[20] F. Al-mamoori, K. Mansoor, E. M. Mallah, and F. W. D. Elhajji, 'Pharmacodynamic and Pharmacokinetic Interaction of Warfarin in the Presence of Some Commonly Used Complementary and Alternative Medicines (CAMs) in Rat Plasma by Using HPLC', no. December, 2018.

[21] Alfa Wassermann, 'ACE Alera ${ }^{\circledR}$ Performance Characteristics ACE Alera ${ }^{\circledR}$ Performance Characteristics Alfa Wassermann Open Channel Application Kits', www.AlfaWassermannUS.com, pp. 4-5, 2013.

[22] Y. Chen et al., 'A modified formula for calculating low-density lipoprotein cholesterol values', Lipids Health Dis., vol. 9, 2010.

[23] V. Hirunpanich and A. Utaipat, 'Hypocholesterolemic and antioxidant effects of aqueous extracts from the dried calyx of Hibiscus sabdariffa L . in hypercholesterolemic rats', J. Ethnopharmacol., vol. 103, pp. 252-260, 2006.

[24] L. A. Chalaby, 'Hypolipidemic efficacy of Trigonella Foenum seeds in comparison with Rosuvastatin and Fenofibrate in hyperlipidemic rats', MIDDLE EAST J. Fam. Med., vol. 13, no. 6, pp. 30-38, 2015.

[25] D. Susic, J. Varagic, J. Ahn, M. Slama, and E. D. Frohlich, 'Beneficial Pleiotropic Vascular Effects of Rosuvastatin in Two Hypertensive Models', J. Am. Coll. Cardiol., vol. 42, no. 6, pp. 1091-1097, 2003.

[26] M. Kawaguchi-suzuki et al., 'The Effects of Milk Thistle ( Silybum marianum ) on Human Cytochrome P450 Activity', no. October, pp. 1611-1616, 2014. Y. Cho et al., 'Risk of diabetes in patients treated with HMG-CoA reductase inhibitors', Metabolism., vol. 64, no. 4, pp. 282-288, 2015.

\section{Creative Commons Attribution License 4.0 (Attribution 4.0 International, CC BY 4.0)}

This article is published under the terms of the Creative Commons Attribution License 4.0 https://creativecommons.org/licenses/by/4.0/deed.en_US 